\title{
On the factors controlling occurrence of F-region coherent echoes
}

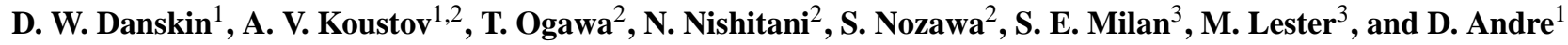 \\ ${ }^{1}$ Institute of Space and Atmospheric Studies, University of Saskatchewan, 116 Science Place, Saskatoon, S7N 5E2 Canada \\ ${ }^{2}$ Solar-Terrestrial Environment Laboratory, Nagoya University, 3-13 Honohara, Toyokawa, Aichi 442, Japan \\ ${ }^{3}$ Department of Physics and Astronomy, University of Leicester, Leicester, LE1 7RH, UK
}

Received: 11 October 2001 - Revised: 25 March 2002 - Accepted: 27 March 2002

\begin{abstract}
Several factors are known to control the HF echo occurrence rate, including electron density distribution in the ionosphere (affecting the propagation path of the radar wave), D-region radio wave absorption, and ionospheric irregularity intensity. In this study, we consider 4 days of CUTLASS Finland radar observations over an area where the EISCAT incoherent scatter radar has continuously monitored ionospheric parameters. We illustrate that for the event under consideration, the D-region absorption was not the major factor affecting the echo appearance. We show that the electron density distribution and the radar frequency selection were much more significant factors. The electron density magnitude affects the echo occurrence in two different ways. For small F-region densities, a minimum value of $1 \times 10^{11} \mathrm{~m}^{-3}$ is required to have sufficient radio wave refraction so that the orthogonality (with the magnetic field lines) condition is met. For too large densities, radio wave strong "over-refraction" leads to the ionospheric echo disappearance. We estimate that the over-refraction is important for densities greater than $4 \times 10^{11} \mathrm{~m}^{-3}$. We also investigated the backscatter power and the electric field magnitude relationship and found no obvious relationship contrary to the expectation that the gradientdrift plasma instability would lead to stronger irregularity intensity/echo power for larger electric fields.
\end{abstract}

Key words. Ionosphere (ionospheric irregularities; plasma waves and instabilities; auroral ionosphere)

\section{Introduction}

Super Dual Auroral Radar Network (SuperDARN) HF coherent radars (Greenwald et al., 1995) are an important instrument for studies of various high-latitude phenomena, especially the ones for which knowledge of plasma convection is essential. In these studies, measured line-of-sight Doppler velocities are used either directly for an individual

Correspondence to: D. W. Danskin

(danskin@dansas.usask.ca) radar or combined together to obtain two-dimensional convection maps. Ideally, convection could be monitored on a global scale but in practice, measurements are limited to those parts of the ionosphere from which strong F-region echoes are received. Recently, Ruohoniemi and Baker (1998) developed a new technique (by applying a polynomial fit to existing data) that allows for the expansion of convection maps beyond the areas of actual radar measurements. For most events, this technique enlarges the area where convection predictions are available. However, for reliable convection estimates, the physical radar coverage is desired to be as large as possible. In spite of good overall "illumination" of the high-latitude ionosphere by the SuperDARN radars (currently, there are 9 radars in the Northern Hemisphere and 6 radars in the Southern Hemisphere), there are occasionally extended spatial regions and prolonged periods of time with low echo occurrence. A natural question is what are the factors that control the appearance of F-regions coherent echoes?

Several factors are known to determine whether F-region coherent echoes can be detected (Fejer and Kelley, 1980; Hanuise, 1983; Tsunoda, 1988; Greenwald et al., 1995). One can divide these factors into two groups: one group is related to the radar wave propagation effects and the other is related to the irregularity production factors. Ruohoniemi and Greenwald (1997), by looking at echo statistics for the Goose Bay HF radar, concluded that there are solar cycle, seasonal and diurnal variations in echo occurrence. In the auroral zone, echoes tend to occur more frequently near the maximum of the solar cycle. This might occur due to the more frequent occurrence of strong electric fields during these years, and thus, the appearance of HF echoes. The echo power are greatly determined by the intensity of ionospheric irregularities. This notion has been recently elaborated on by Ballatore et al. (2001), who showed that echo occurrence is significantly increased during periods of negative interplanetary magnetic field (IMF) $B_{z}$ component conditions, when magnetospheric merging is enhanced and when stronger electric fields are expected. With respect to the season, Ruohoniemi 


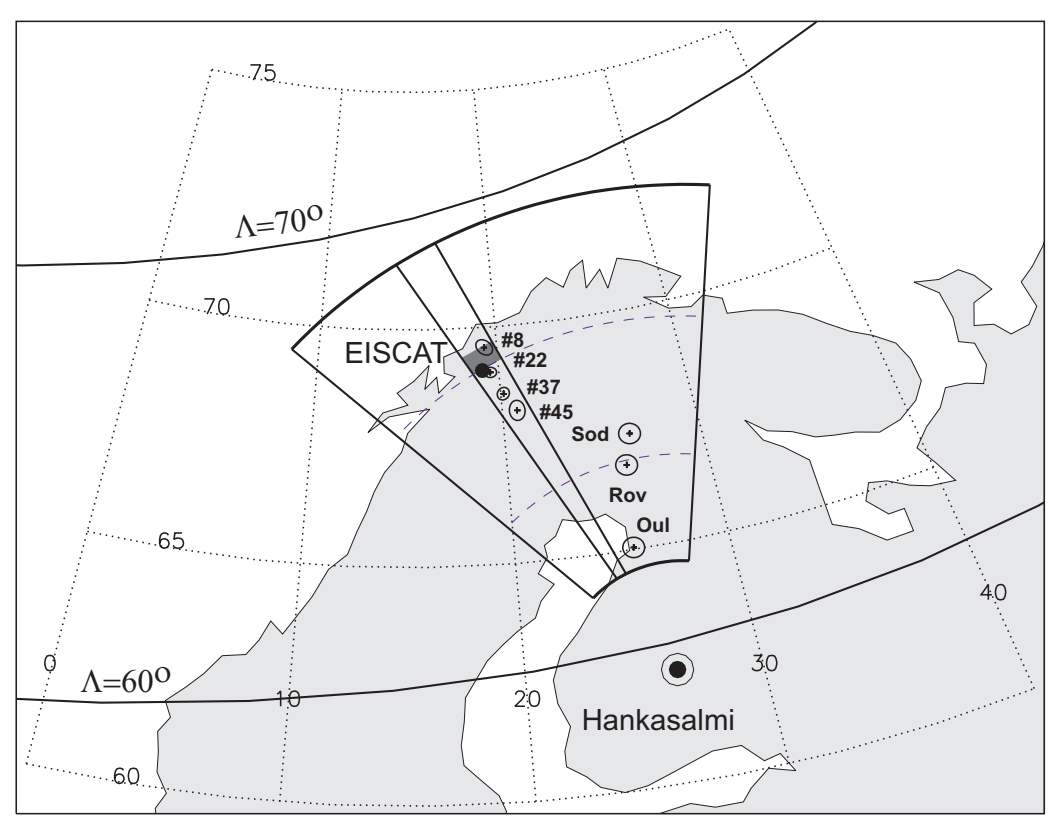

Fig. 1. Field-of-view of the Hankasalmi CUTLASS HF radar for ranges in between 400 and $1200 \mathrm{~km}$ at the height of $300 \mathrm{~km}$. Dashed lines are 600 and $900 \mathrm{~km}$ slant range marks. The outlined sector is the location of beam 5 with the shaded area corresponding to the range bin 16. The solid dot shows the area where ionospheric parameters were measured by the EISCAT incoherent scatter radar. Circles with pluses inside indicate the field-of-view for the Finnish riometers at a height of $90 \mathrm{~km}$. Ellipses with pluses indicate the beam projections at $90 \mathrm{~km}$ for the IRIS beams as indicated. Also shown are PACE lines of equal magnetic latitudes of $\Lambda=60^{\circ}$ and $\Lambda=70^{\circ}$.

and Greenwald (1997) concluded that auroral zone echoes occurred more frequently during winter for the direct propagation mode, when radio waves reached the ionospheric irregularities by means of mildly refracted propagation. The lack of echoes during summer was interpreted as an effect of solar radiation in the sunlit ionosphere smoothing out the plasma gradients and reducing irregularity production. Ruohoniemi and Greenwald (1997) did not discuss the diurnal variations, but their diagrams show that echoes tend to occur more frequently during late afternoon-midnight-morning hours, although this depends strongly on the season. This might again be indicative of the importance of the irregularity production effects.

On the other hand, Milan et al. (1997), by investigating 20-month statistics for the Co-operative UK Twin Located Auroral Sounding System (CUTLASS) HF radars in Northern Scandinavia, concluded that the electron density in the ionosphere contributes strongly to the echo appearance at a specific range. These authors described changes in the radar wave propagation modes and pointed out that the proper amount of refraction is a very important factor leading to preferential time sectors and radar ranges for echo detection. In addition, they also observed that the low echo occurrence during the winter daytime for short distances is due to a lack of irregularities in the sub-auroral ionosphere. Finally, they confirmed the low echo occurrence during summer. Milan et al. (1997) reported a general decrease in F-region echoes with magnetic activity increase. Ballatore et al. (2001) also noted that there was no clear correlation between the polar cap echo occurrence and the merging electric field intensity, indicating other factors need to be considered.

To find the reason for the F-region echo appearance, namely the threshold conditions, perhaps one needs to determine all of the factors that control the power of echoes when they exist. In the past, only a few attempts have been made in this direction (e.g. Villain et al., 1986; Milan et al., 1999; Fukumoto et al., 2000), mostly due to the difficulty of the measurements of ionospheric parameters within the radar scattering volume. In this study, we combine HF data gathered by the CUTLASS Hankasalmi radar with ionospheric measurements performed by the EISCAT incoherent scatter radar and riometer observations along the HF radar beam. We consider an almost 4-day long period in February 1999 and basically employ an approach of Milan et al. (1999).

\section{Experiment}

In Fig. 1, we show the location of the CUTLASS Hankasalmi $\mathrm{HF}$ radar $\left(62.3^{\circ} \mathrm{N}, 26.6^{\circ} \mathrm{E}\right)$ and its viewing zone between the ranges of 400 and $1200 \mathrm{~km}$ at the height of $300 \mathrm{~km}$. The radar was operated in the high time resolution mode with beam scanning through 16 positions over $1 \mathrm{~min}$. We concentrate here on observations in beam 5 whose orientation is showed in Fig. 1 by straight lines within the overall viewing zone. This beam was selected because it overlaps with the region where ionospheric parameters were monitored by the incoherent scatter radar EISCAT (solid circle). The HF radar integration time was around $3 \mathrm{~s}$ and the range resolution was $45 \mathrm{~km}$ with a starting range of $180 \mathrm{~km}$. The operating 


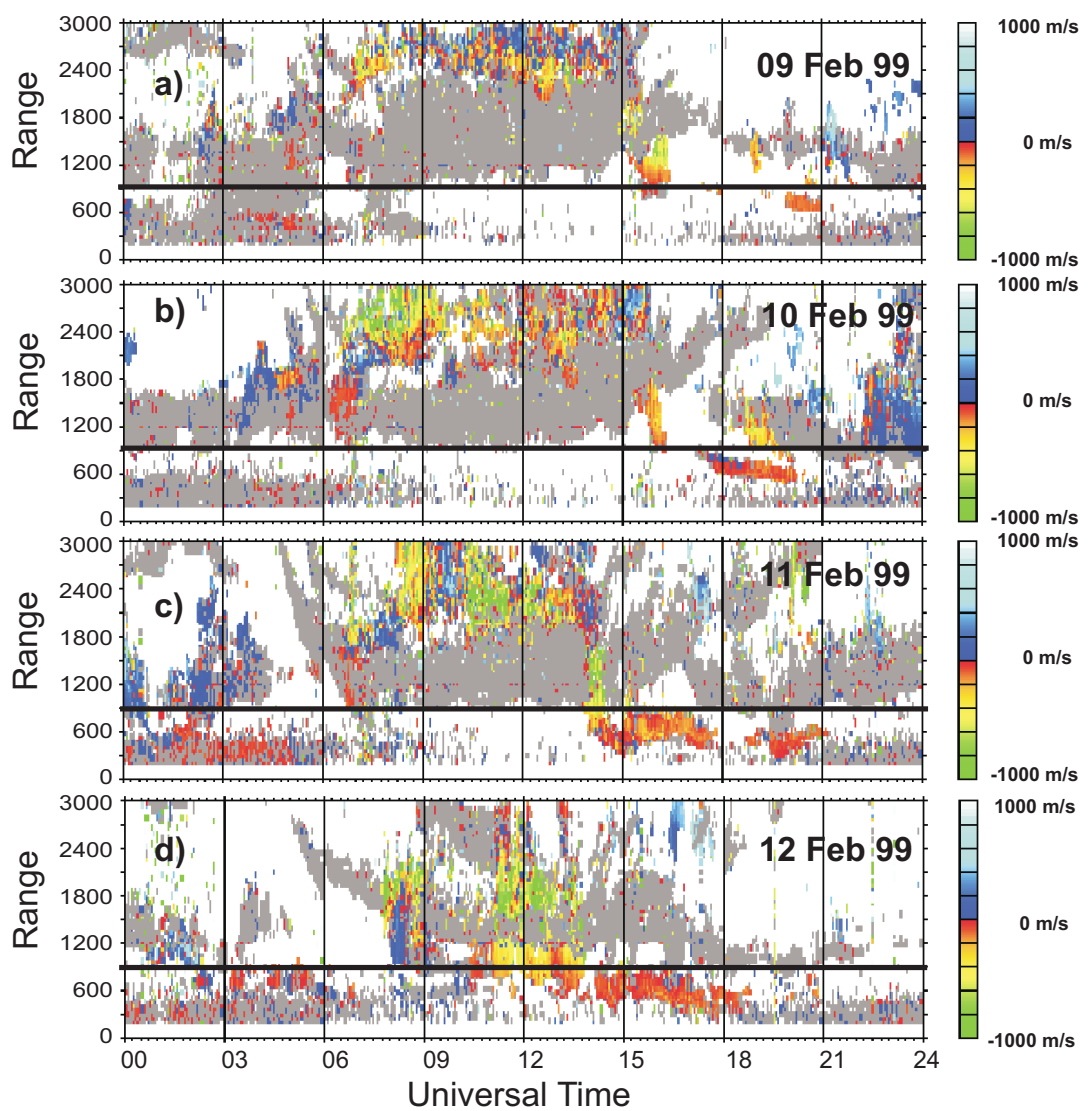

Fig. 2. (a)-(d) Doppler velocity measured by the CUTLASS Hankasalmi radar in beam 5 on 9-12 February 1999. Horizontal solid line at $900 \mathrm{~km}$ shows the range corresponding to the area where measurements were made by the EISCAT incoherent scatter radar. The gray color denotes the ground scatter. MLT $=\mathrm{UT}+2 \mathrm{~h}$.

frequency was chosen to be $10.0 \mathrm{MHz}$ during nighttime and 12.4 $\mathrm{MHz}$ during daytime, to optimize the echo occurrence rate.

The EISCAT UHF radar worked in CP-1K mode with the remote antennas at Kiruna (Sweden) and Sodankylä (Finland) being oriented to a common area at a height of $250 \mathrm{~km}$, where additional Doppler velocity measurements were performed by the Troms $\varnothing$ receiving antenna along the magnetic flux line. Such an arrangement allowed for tri-static electric field measurements in the area close to bin 16 (slant range of $900 \mathrm{~km}$ ) of the CUTLASS Hankasalmi radar. In addition to the electric field measurements, the electron density distribution with height was derived from the power of the return signals at Troms $\varnothing$. The altitude resolution for EISCAT density measurements was $22 \mathrm{~km}$ for the long pulse method in the F-region, and $3.1 \mathrm{~km}$ for the alternate code method in the E- and D-regions. We considered 2-min averaged EISCAT data in this study to have a time resolution as close as possible to the HF radar integration time.

Finally, estimates of non-deviative D-region absorption for $\mathrm{HF}$ radio waves were obtained from the 38.2-MHz Imaging Riometer for Ionospheric Studies (IRIS) facility located at Kilpisjarvi, Finland $\left(69.1^{\circ} \mathrm{N}, 20.8^{\circ} \mathrm{E}\right)$ and from Finnish riometer stations at Oulu, Rovaniemi and Sodankylä. The field-of-view at a height of $90 \mathrm{~km}$ for the Finnish riometers and four IRIS beams are indicated by circles and ellipses, respectively, with a plus sign indicating the center of the beam. The Finnish stations are located closer to the HF radio wave entry point into the D-region of ionosphere where the majority of absorption occurs.

\section{Overview of the observational period}

We consider the 4-day period of 9-12 February 1999, Figs. 2a-d. The Hankasalmi HF radar observed echoes quite often throughout this interval, although many of the echoes were ground scatter, as indicated in Fig. 2 in gray. Ground scatter is observed when radio waves are refracted to the ground by the ionosphere and reflected back from the ground (for illustrations, see, for example, Villain et al., 1984). Ground scatter was especially strong between 06:00 UT and 18:00 UT, roughly from local sunrise to local sunset (MLT $=\mathrm{UT}+2 \mathrm{~h}$ ). Most of the ground scatter was at slant ranges larger than the EISCAT observation spot (bin 16, range of $900 \mathrm{~km}$ ), indicated in Fig. 2 by a solid line. Also, short distance meteor-like sporadic echoes were observed most of the time in the evening-midnight-morning sector. 


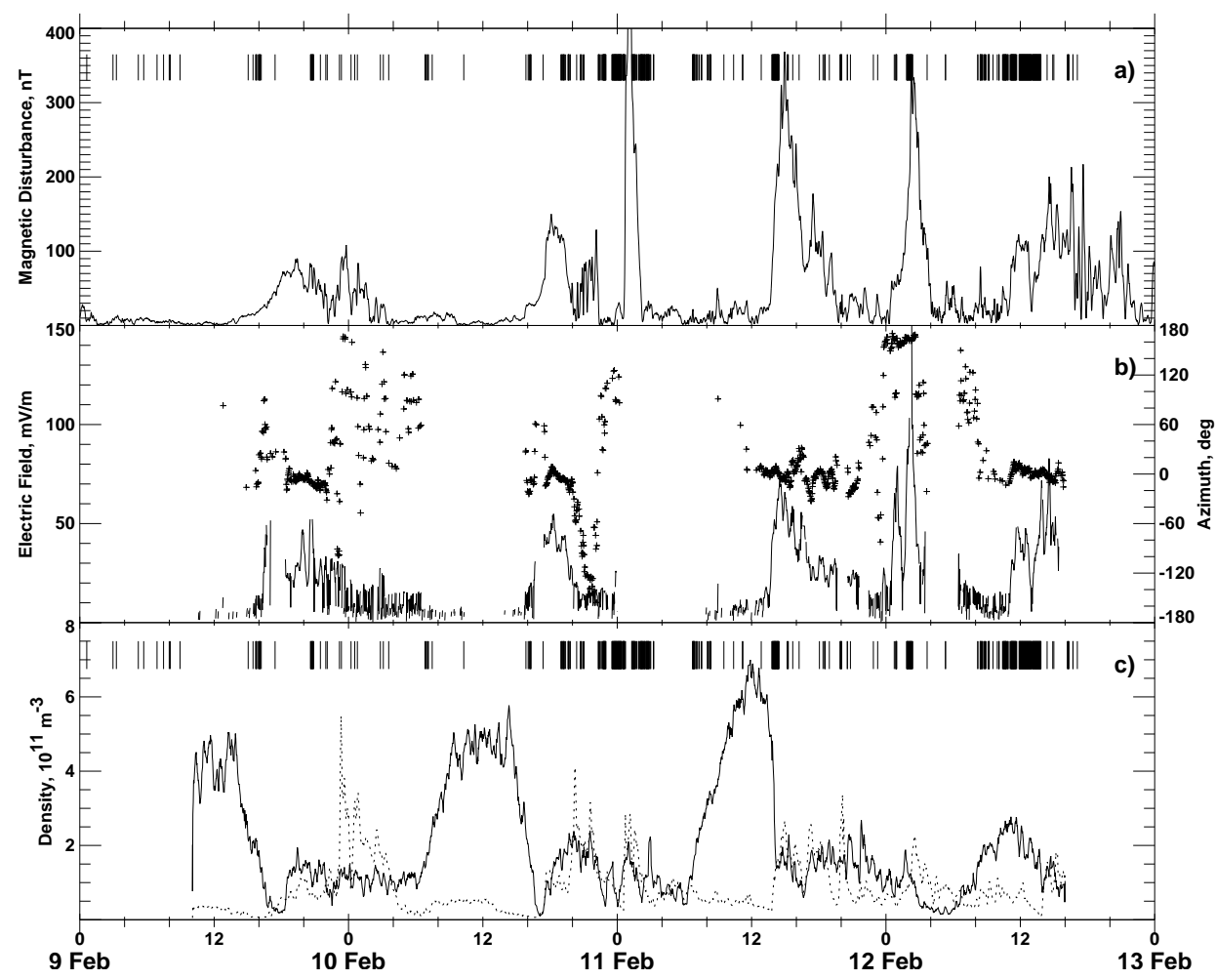

Fig. 3. (a) Horizontal magnetic perturbations at Troms $\varnothing$, (b) electric field magnitude (solid line) and azimuth (crosses), and (c) electron density at $250 \mathrm{~km}$ (solid line) and $110 \mathrm{~km}$ (dots). Vertical bars in panels (a) and (b) indicate the times of HF echo occurrence in beam 5 , bin 16.

In this study, we are concerned about ionospheric scatter only. For all 4 days, such echoes were observed mostly at large ranges of $2000-3000 \mathrm{~km}$ (Figs. 2a-d). It is very likely that these echoes were received through the $1 \& 1 / 2$ hop propagation mode, when the radio waves experienced refraction in the F-layer, ground reflection and propagation to the scatter points with return along the same path. On 9, 10 and 11 February, the F-region densities between $\sim 10: 00$ UT and $\sim$ 15:00 UT were favorable for maintaining this mode (Milan et al., 1997), as we will show later.

On 9 February, with the electron density decrease after 15:00 UT, near local sunset time, echoes started to be received at shorter and shorter distances so that between 16:00 and 21:00 UT, the echo band was seen over the EISCAT spot. This general morphology of ionospheric and ground scatter repeated on other days. On 12 February (Fig. 2d), much more ionospheric scatter was detected over the EISCAT spot during noon hours.

The first 2 days were magnetically quiet, with $K_{p}$ indices being around 1 , while the other 2 days were moderately disturbed with typical $K_{p}$ indices ranging between 3 and 4 (Coffey, 1999). Total horizontal magnetic perturbations (absolute value with respect to the background lines for $X$ - and $Y$-components) at a magnetic station near the EISCAT spot (Troms $\emptyset$ ) are presented in Fig. 3a. Very minor perturbations $(<100 \mathrm{nT})$ are seen on 9 and 10 February, and much more significant perturbations (up to $300 \mathrm{nT}$ ) in the evening and midnight MLT sectors on 11 and 12 February (for Troms $\varnothing$, roughly, MLT $=\mathrm{UT}+2 \mathrm{~h}$ ). In Figs. $3 \mathrm{a}$ and $\mathrm{c}$, we indicate, by vertical bars, the times for the ionospheric HF echo appearance over the EISCAT spot. A general trend seems to indicate that HF echoes occur during times of magnetic disturbance; however, HF echoes were detected quite often during periods of very low disturbances (10 February, 10:00 UT; 11 February, 06:00-08:00 UT). Also, one can notice an absence of echoes during periods of strongest magnetic disturbances (11 February, 01:00 UT, 14:00 UT; 12 February, 02:00 UT).

Throughout the considered period, the EISCAT radar was operated almost continuously. EISCAT data were available starting from 10:00 UT on 9 February all the way to 16:00 UT on 12 February with an 8-h gap in electric field data on 11 February. The electric field (Fig. 3b) exhibited enhancements during the evening and midnight hours for all days. EISCAT measurements of the ionospheric electron density at $110 \mathrm{~km}$ (E-region) and $250 \mathrm{~km}$ (F-region) are presented in Fig. 3c. In terms of F-region electron densities, the 9, 10, and 11 February events were very much typical, with densities reached around $(5-7) \times 10^{11} \mathrm{~m}^{-3}$ in the daytime sunlit ionosphere (sunrise and sunset times are around 06:00 UT and 15:00 UT, respectively). On 12 February, the daytime F-region densities were about 2 times smaller than the previous days. Eregion densities were varying sporadically during each day. This is not a surprise since the Sodankylä ionosonde registered sporadic E-layer activity on each day, especially in the 


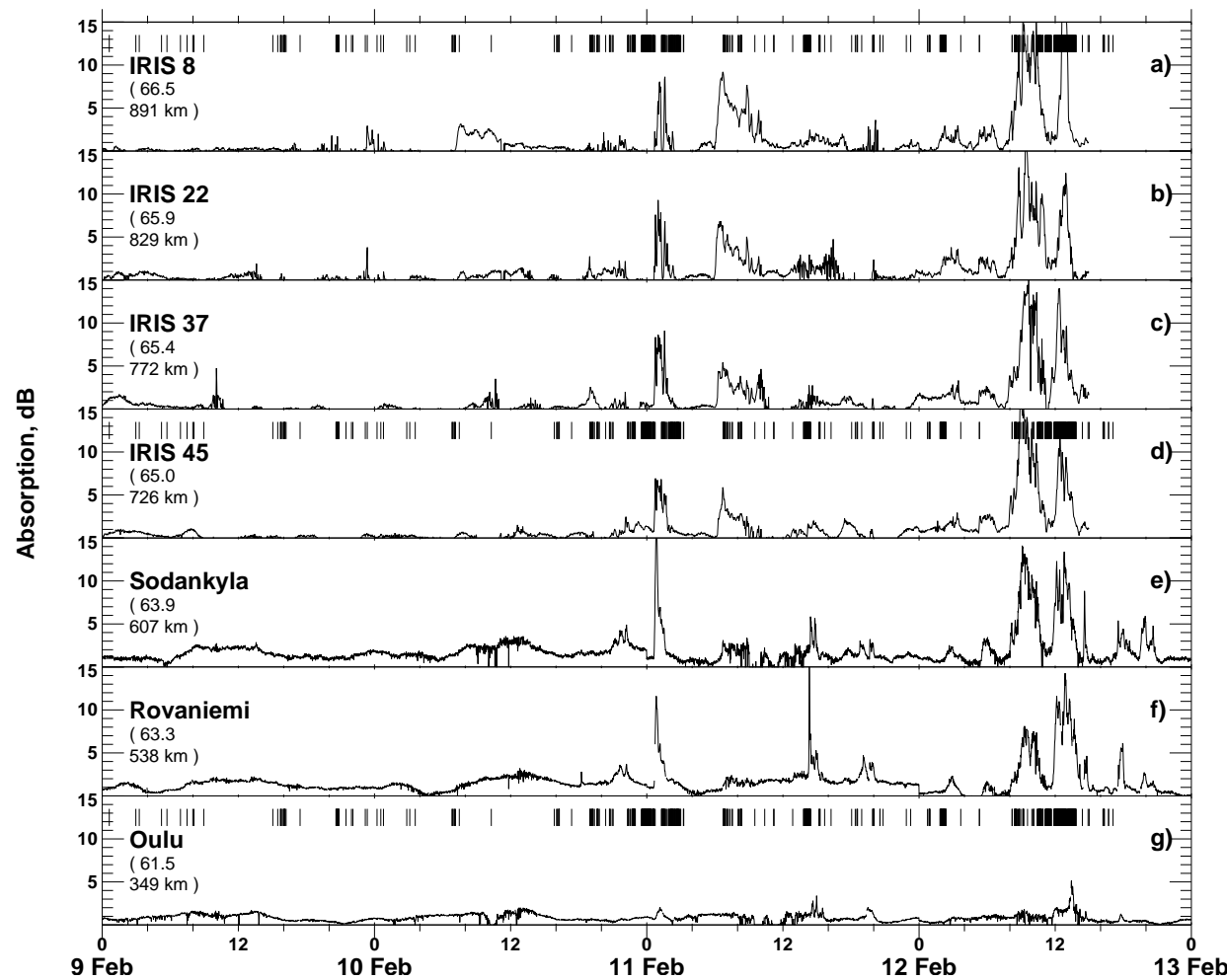

Fig. 4. (a)-(g) Variations of D-region absorption at $12 \mathrm{MHz}$ determined by riometers near CUTLASS beam 5, see Fig. 1. Absorption was estimated from original riometer records by applying the $f^{-2}$ dependence, where $f$ is the riometer frequency. Vertical bars in panels (a), (d) and $(\mathrm{g})$ indicate the times of HF echo detection over the EISCAT spot of measurements.

evening and midnight sectors. Clearly, the observed magnetic perturbations were related to both variations of the electric field magnitude and electron density in the E-layer.

On 10 February, very few ionospheric echoes were observed at the EISCAT spot during daytime perhaps partly due to a fairly low electric field, less than $10 \mathrm{mV} / \mathrm{m}$ (often even several times smaller). With an electric field increase during evening hours, matched with a decrease in the F-region electron density (due to sunset), echoes started to appear more frequently, especially around magnetic midnight, where Fregion densities were favorable for direct propagation mode. Between 17:00 UT and 20:00 UT, a band of E-region echoes was observed at closer ranges of $\sim 700 \mathrm{~km}$.

For 11 February, electric field data were not available for the first $8 \mathrm{~h}$, during which there were some echoes obtained through the direct propagation mode to the EISCAT spot. Later during the day, echoes were observed again for moderate values of F-region electron density and electric field.

On 12 February, simple eye inspection shows that HF echo occurrence at the EISCAT spot correlates well with the period of moderate F-region densities of $2 \times 10^{11} \mathrm{~m}^{-3}$, low E-region densities of less than $1 \times 10^{11} \mathrm{~m}^{-3}$ and occasionally, an enhanced electric field. With the increase of the Eregion electron density after 14:00 UT, echoes were observed at ranges $\sim 600 \mathrm{~km}$. Elevation angle measurements indicate that these were E-region echoes.

D-region absorption determined by the riometers near
CUTLASS beam 5 is shown in Fig. 4. Absorption was recalculated from the original riometer records (at frequencies $30-50 \mathrm{MHz}$ ) to the equivalent frequency of $f=12.4 \mathrm{MHz}$ using $f^{-2}$ dependence. Clearly, absorption is almost negligible during the first two days and there are some enhancements during the other two days, especially in the midnight sector. Also, absorption is larger at higher latitudes, as expected in the auroral zone. One can notice that for some periods, during the considered 4 days (e.g. 10 February, 10:00-16:00 UT) echoes were not detected. During these periods enhanced absorption was observed at low latitudes (e.g. Rovaniemi riometer, Fig. 4f), suggesting that absorption might be a factor in the echo disappearance. On the other hand, one can see that on 12 February, echoes were in abundance, even though the absorption was the strongest over the 4-day period. One should also note that there were extended periods when absorption was really small while echoes were not observed.

\section{Relationship of echo power and various ionospheric parameters}

From the above review of the period under study, one can conclude that there is no one single factor that dominantly controls the HF echo appearance. In this section, we explore data for those times when HF echoes were observed. We 

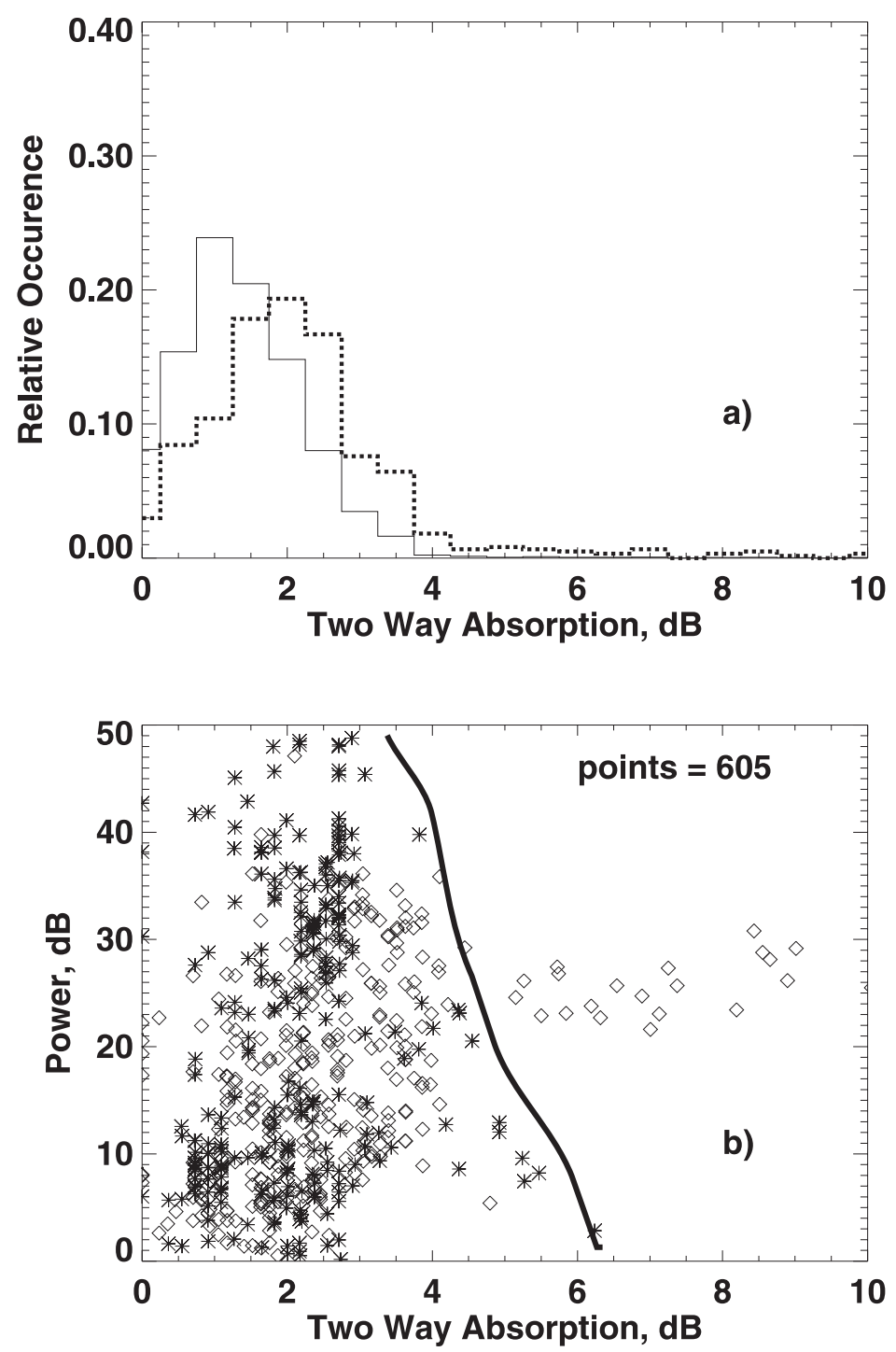

Fig. 5. (a) Histogram of the relative occurrence of riometer absorption at Oulu for all four days (solid line) and for all times when HF ionospheric echoes were received (dotted line). (b) Scatter plot of HF echo power in bin 16 versus D-region absorption at slant range of $\sim 350 \mathrm{~km}$ obtained from the original riometer records at Oulu, the closest station to the entry point of radar waves into the D-region (605 points). Asterisks (diamonds) correspond to observations at $10.0(12.4) \mathrm{MHz}$.

compare echo power with each of the ionospheric parameters in order to reveal any kind of relationship.

\subsection{D-region absorption}

Figure $5 b$ shows echo power versus D-region two-way absorption calculated for the radar frequency of 12.4 (10) MHz at the Oulu riometer location. The histograms of occurrence of riometer absorption (Fig. 5a) for the entire 4 days (solid line) and riometer absorption when ionospheric scatterers were present during the 4 days (dotted line) indicate that ionospheric scatterers are most likely when the absorption is of the order of $2 \mathrm{~dB}$. One can see that echoes are more intense for small amounts of absorption, less than $3 \mathrm{~dB}$, with the exception of a "separate" cloud of 20 points at $\sim 25 \mathrm{~dB}$. These exceptional data came from observations on 12 February, around 13:30 UT (see the spike in absorption on Fig. 4g). The line in Fig. 5b (drawn by hand) determines the limits of the echo power for various amounts of two-way absorption.
This line shows a tendency for the echo power to decrease with absorption, which is expected. However, the majority of observed echoes correspond to small absorption values and the conclusion from this graph is that if F-region echoes occur, the amount of absorption does not substantially reduce their power nor completely absorb the radar waves. Similar conclusions were drawn from the comparison of echo power with absorption at other riometer locations.

\subsection{Electron density and radio wave propagation}

Previous studies have shown that both E- and F-region densities can be important for the F-region echo appearance (e.g. Milan et al., 1999). Electron density distribution in the ionosphere controls, first of all, the amount of refraction for observations at a specific range, e.g. Villain et al. (1984). In order to study the role of refraction in our measurements, we temporally assume that F-region irregularities occupy all heights, from the bottom to the top of the F-region. Then the 


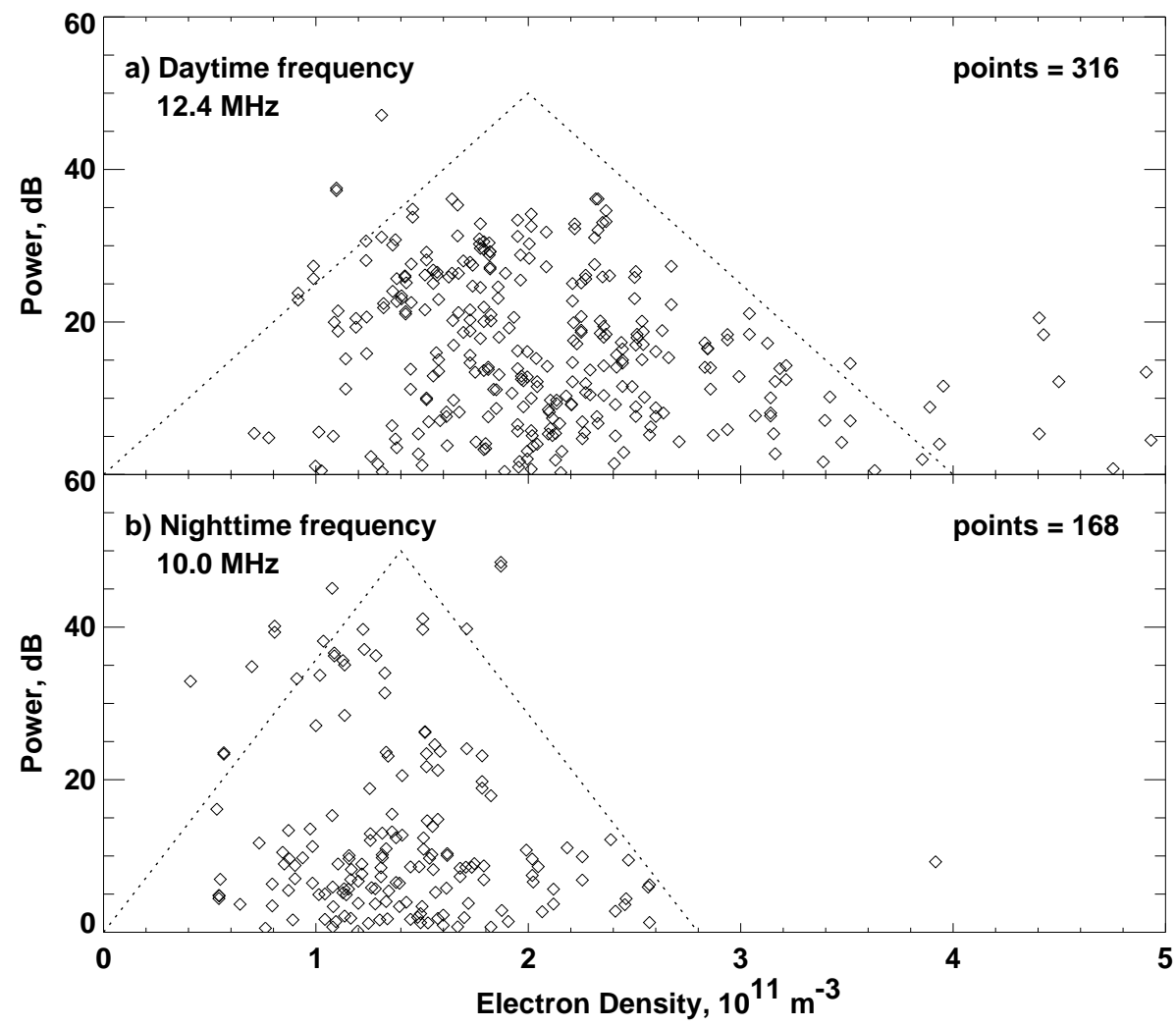

Fig. 6. Echo power versus electron density at the height of $250 \mathrm{~km}$ (a) for the daytime observations at $12.4 \mathrm{MHz}$ ( 316 points) and (b) for the nighttime observations at $10.0 \mathrm{MHz}$ (168 points). Dotted lines roughly encompass the maximum power observed for each electron density at $250 \mathrm{~km}$.

only concern is an appropriate amount of refraction for the radio waves to reach magnetic flux lines orthogonally within the scattering volume.

In Fig. 6, we present the power of observed echoes versus electron density at the height of $250 \mathrm{~km}$. The available data were split into two sets: the top panel shows daytime observations performed at the radar frequency of $12.4 \mathrm{MHz}$, while the bottom panel shows similar data for the nighttime observations at the radar frequency of $10.0 \mathrm{MHz}$. The tendency is clear; there is an optimal density that provides the greatest echo power for each radar frequency. These optimal values are around $2.0 \times 10^{11} \mathrm{~m}^{-3}$ for at $12.4 \mathrm{MHz}$ and $1.4 \times 10^{11} \mathrm{~m}^{-3}$ at $10.0 \mathrm{MHz}$. We interpret this result as follows. At densities smaller than the optimal values, the amount of refraction is not enough to meet the orthogonality condition within the expected area of scatter, while for higher electron density over-refraction occurs and again, the orthogonality condition is not met.

To explore what optimal density means in terms of radio wave propagation for our observations, we made a series of ray tracing modeling for the electron density profiles typically observed by EISCAT during periods of echo registration. We assumed that the density only varies with altitude, since two-dimensional measurements of the profiles are not available in the CP1 mode. By the identification of common radar features predicted by the ray tracing, we believe this approach is a valid first order approximation. In Fig. 7a, we show three 10-min electron density profiles, as measured by EISCAT at 12:30 UT on 10 February (case (i)), and at 12:30 UT (case (ii)) and 14:30 UT (case (iii)) on 12 February. In Figs. $7 \mathrm{~b}-\mathrm{d}$, we show the slant ranges and altitudes of expected backscatter (with aspect angles within $\pm 1^{\circ}$ range) by crosses along specific rays where the rays correspond to elevation angles of $6^{\circ}-30^{\circ}$ in $2^{\circ}$ steps.

In Fig. 7b, we show that for electron densities typical for daytime observations on several days, there are no chances to receive direct F-region echoes at $\sim 900 \mathrm{~km}$, but there are opportunities to receive $1 \& 1 / 2$ hop signals at $\sim 2500 \mathrm{~km}$. Also, reception of ground scatter is very likely from 1200 $2800 \mathrm{~km}$. Ionospheric echoes are expected to come from the altitudes of $190-250 \mathrm{~km}$ with elevation angles of $20^{\circ}-30^{\circ}$. These values of elevation angles are in reasonable agreement with radar measurements. This diagram also predicts that echoes (from both E- and bottom F-regions) can be obtained from short distances, but they were not detected according to Fig. 2b, except for sporadic traces of echoes at near ranges of $300-600 \mathrm{~km}$. We believe that E-region echo absence is related to the low electric field observed at this time.

Figure $7 \mathrm{c}$ shows how propagation is affected due to a substantially decreased F-region density, as was typical during the daytime of 12 February. One can see no $1 \& 1 / 2$ hop propagation mode here. After 14:00 UT, the E-region elec- 

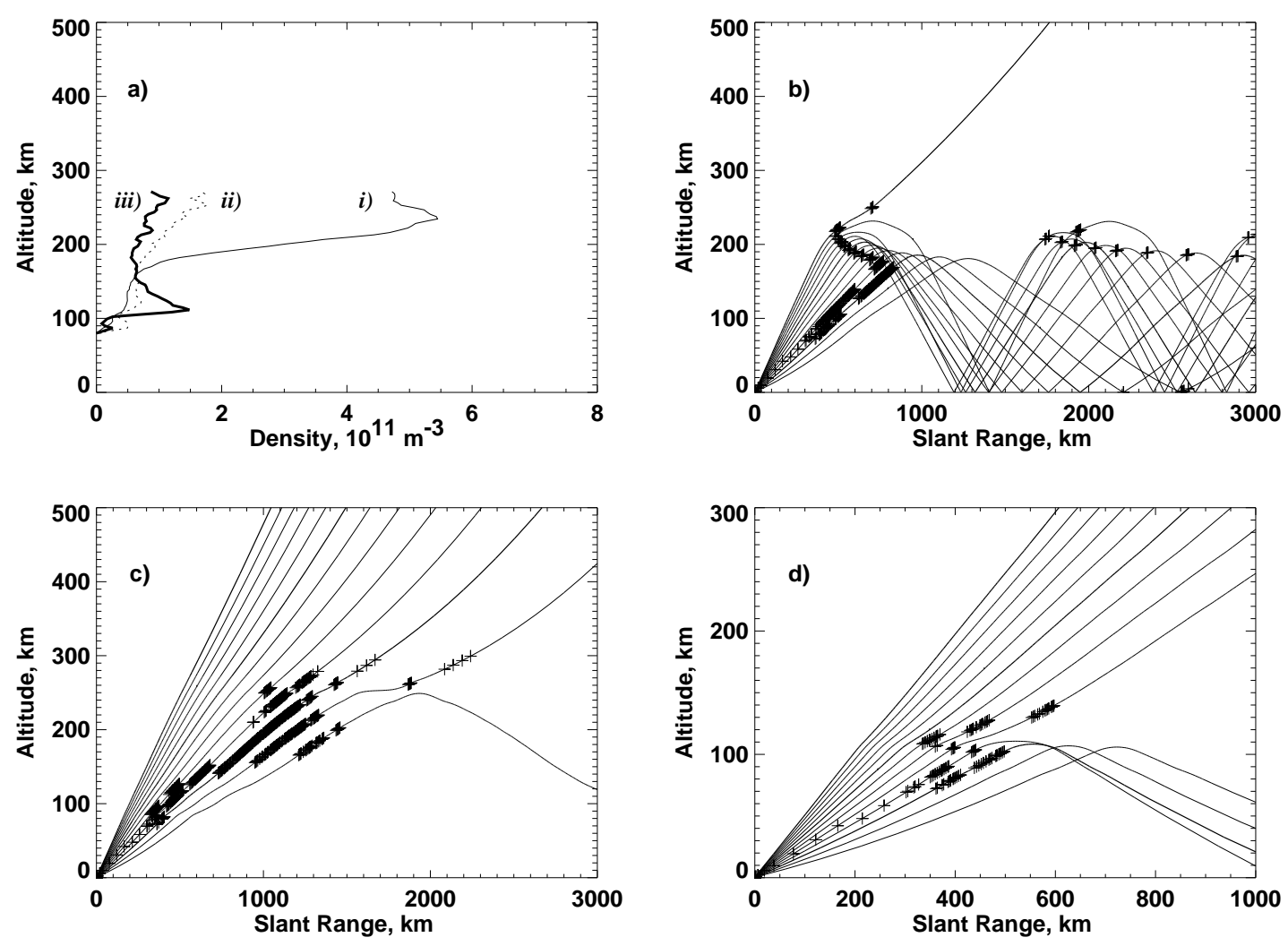

Fig. 7. (a) The electron density distribution in the ionosphere used in ray tracings (b)-(d) and possible ray paths for $12.4 \mathrm{MHz}$ observations from Hankasalmi for (b) 10 February 12:30 UT, using profile i), (c) 12 February 12:30 UT, using profile ii), and (d) 12 February 14:30 UT, using profile iii). Crosses indicate ranges where the ray is within $\pm 1^{\circ}$ of orthogonality to the magnetic field.

tron density was enhanced, which caused the rays to reach orthogonality only in at E-region altitude and at much shorter ranges, as depicted in Fig. 7d. Thus, ray tracing supports our conclusions on the propagation modes that were in effect during our measurements.

Another way the electron density distribution can affect the appearance of F-region irregularities is through slowing down the gradient-drift (GD) instability responsible for the irregularity excitation. This happens due to shorting out the polarization electric field in growing GD modes (Vickrey and Kelley, 1982; Chaturvedi et al., 1994). We will explore this effect in the next sub-section, since it is closely related to the intensity of the electric field in the ionosphere.

\subsection{Electric field intensity}

The existence of ionospheric irregularities of appropriate scale size ultimately determines the appearance of auroral echoes; without the irregularities no return echo could be detected. Unfortunately, not much is known about the properties of F-region irregularities of decameter scale (Fejer and Kelley, 1980; Hanuise, 1983; Tsunoda, 1988). In the auroral zone, the most likely mechanism of F-region irregularity formation is the gradient-drift instability. The positive contribution to the growth rate of the GD instability is determined by the electric field magnitude, the scale of the back- ground gradient and their mutual orientation (Keskinen and Ossakow, 1982). Damping of the GD waves is determined by the diffusion (dependent on the temperatures and collision frequencies of charged particles). As mentioned above, diffusion can be enhanced in the presence of highly conducting E-layer (Vickrey and Kelley, 1982). According to Vickrey and Kelley (1982), the effect is determined by the parameter $\zeta=1-M^{-1}$, where $M=1+\Sigma_{p}^{F} / \Sigma_{p}^{E}$ and $\Sigma_{p}^{E}$ and $\Sigma_{p}^{F}$ are the height integrated Pedersen conductances of the Eand F-layers, respectively. For a poorly conducting E-layer, $\Sigma_{p}^{E} \rightarrow 0, M \rightarrow \infty$ and $\zeta \rightarrow 1$. For a highly conducting Elayer, $M \rightarrow 1$ and $\zeta \rightarrow 0$ and the growth rate of the GD instability is greatly decreased. In this section, we explore the role of both these factors in observations of F-region echoes.

Figure 8 is a scatter plot of echo power versus electric field magnitude separated once again into daytime and nighttime events. There is a significant data spread here; however, during the daytime, points seem to show a power increase, as indicated by the shaded circles which represent the average power in each $10 \mathrm{mV} / \mathrm{m}$ electric field bin. Overall, one can say that a stronger electric field is preferred. For the nighttime, no such trend is seen. However, for the night-time frequency, there does appear to be a limit in the electric field of about $20 \mathrm{mV} / \mathrm{m}$ above which the power does not exceed $20 \mathrm{~dB}$. Indeed, some echoes observed at electric fields as high as $80 \mathrm{mV} / \mathrm{m}$ were of low intensity. 


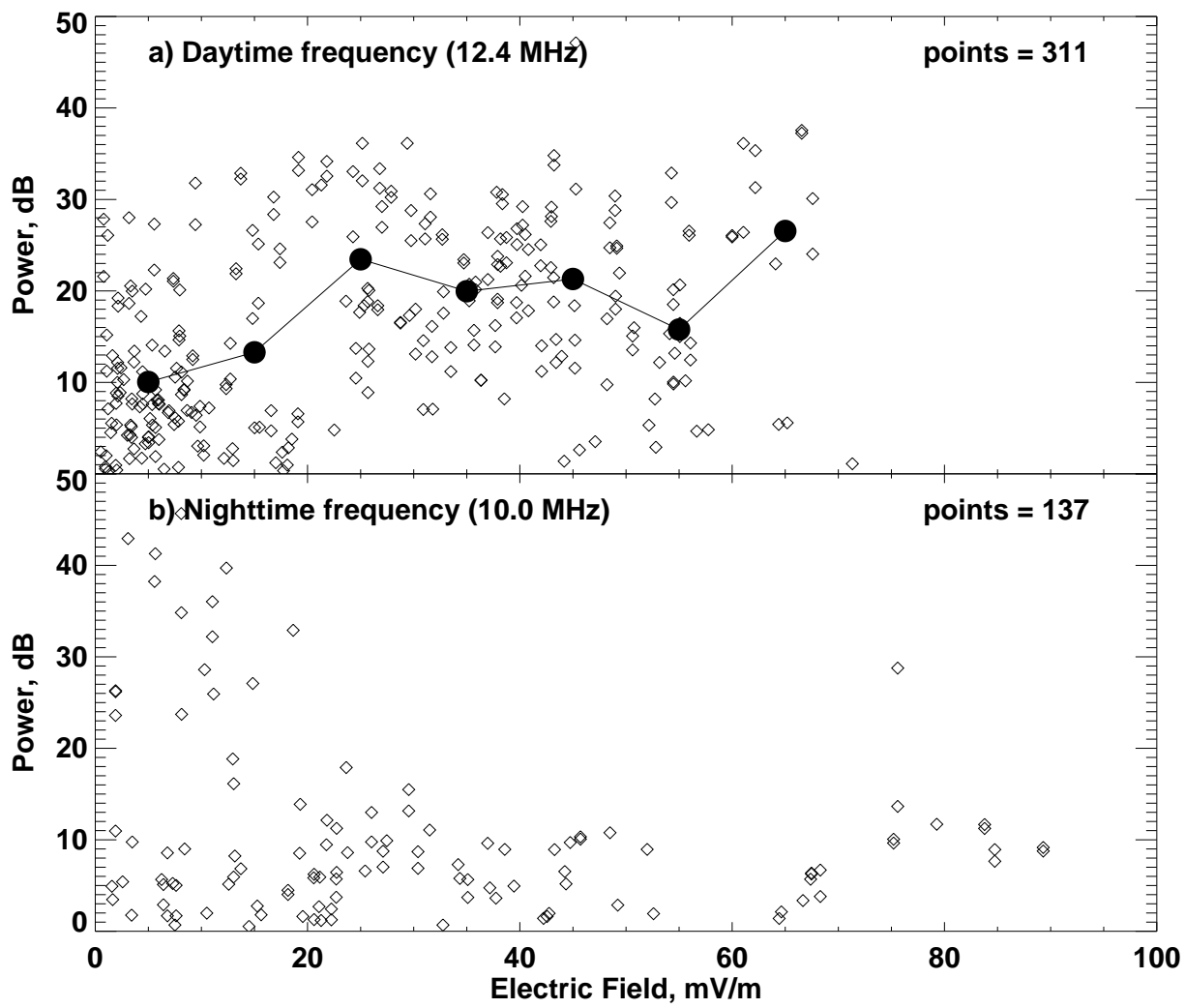

Fig. 8. Scatter plot of echo power versus electric field magnitude for all echoes observed over 4 days (a) for daytime observations at $12.4 \mathrm{MHz}$ (311 points) and (b) for nighttime observations at $10.0 \mathrm{MHz}$ (137 points). Shaded circles in (a) indicate the average power in the associated $10 \mathrm{mV} / \mathrm{m}$ electric field bin.

In Fig. 9, we explore the effect of a conducting E-layer on the echo appearance. We plot here the height-integrated conductances of the E- and F-layers and the parameter $M$ for the times when EISCAT density measurements are available. We represented the E-layer arbitrary as being contained between 90 and $140 \mathrm{~km}$, with the F-layer being spread over altitudes above $140 \mathrm{~km}$, similar to Milan et al. (1999). We also indicate by vertical bars in Fig. 9c the times for the echo appearance over the EISCAT spot. The general impression from Fig. 9 is that echoes are mostly observed during the times of low values of the $M$ factor. Contrary to expectation, every time $M$ was enhanced at noon, very few echoes were seen. One should note that periods of high $M$ values typically also coincide with periods of low electric field, so the judgment on the importance of the effect is difficult to ascertain. For example, on 11 February, the echoes were seldom between 08:00 UT and 13:00 UT, even though the $M$ value was enhanced and the electric field was about $10 \mathrm{mV} / \mathrm{m}$ or so. On the other hand, on 12 February, at $\sim 02: 00$ UT, echoes were observed, as predicted, when the $M$ values were enhanced, perhaps due to a simultaneously enhanced electric field.

One important feature of the data presented in Fig. 9 worth mentioning is that the observations right at the end of the period on 12 February at 14:00-15:00 UT show $M$ values to be unusually low, while the electric field was strong, but no echoes were observed. To clarify this point, we present data for 12 February, 10:00-16:00 UT in Fig. 10 with better time resolution than data in Fig. 9. One can see the effect easily as the value of $M$ approaches 1; the instability is inhibited. However, this is not the likely reason for the lack of F-region echoes at this time. As we discussed in Sect. 4.2, echo disappearance at this time is very likely due to enhanced density in the lower portion of the ionosphere, so that HF radar waves are refracted to smaller heights and closer ranges (Fig. 7d). Another similar event is around 11:40 UT on this day.

On the other hand, looking at Fig. 10 and Fig. 7c, one can notice that short-lived echo disappearance is not always related to propagation effects. For example, around 13:00 UT, there was no significant redistribution of electron density (no change in conductance), but echoes disappeared, perhaps due to the decrease in electric field magnitude.

\section{Discussion}

Over the last decade, statistics for various parameters of Fregion HF coherent echoes have been reported, including power, spectral width and velocity (Milan et al., 1997; Milan and Lester, 1998; Huber, 1999; Fukumoto et al., 1999, 2000; Hosokawa et al., 2001, 2002). However, not much attention has been paid to a fundamental question on the major factor(s) controlling the appearance of such echoes. Certainly, 


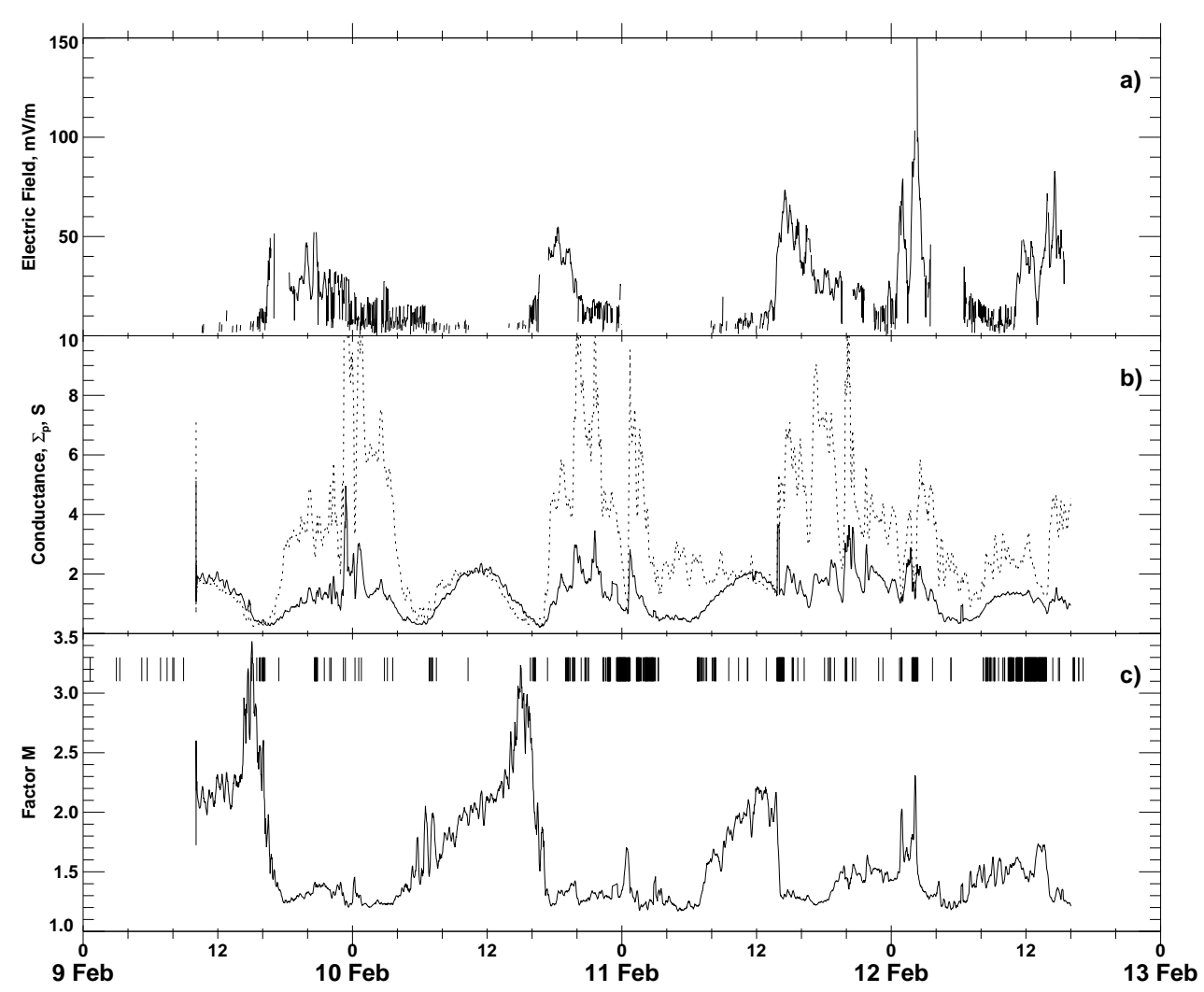

Fig. 9. Temporal variations of (a) the electric field, (b) the height-integrated Pedersen conductances in the F- and E-regions (solid line and dots, respectively), (c) the parameter $M=1+\Sigma_{p}^{F} / \Sigma_{p}^{E}$ influencing the growth rate of the F-region gradient-drift instability in the presence of conducting E-region and HF echo occurrence over the EISCAT spot (vertical bars).

it is not easy to address this question without reliable knowledge of irregularity availability and of plasma parameters all along the propagation path of the HF radar wave, including, of course, the scattering volume. It is important to realize that at HF, several propagation modes are important, so that an assessment of various factors certainly should take this circumstance into account.

In this study, we consider the simplest case when F-region echoes are received through the direct F-region propagation mode. In this case, radio waves reach F-region irregularities through the appropriate amount of refraction (this mode is also called 1/2F mode, Milan et al., 1997). But even for this simple situation, we had a very limited data set to work with. Namely, we had measurements of electron densities at the scattering volume and extrapolated these measurements along the HF radar beam. One should also bear in mind that the areas of EISCAT and CUTLASS effective collecting volumes are quite different for each instrument. EISCAT measures parameters in an area with a diameter of $\sim 3 \mathrm{~km}$ at the height of $250 \mathrm{~km}$, while the effective area for the CUTLASS radar has dimensions of $\sim 45 \mathrm{~km} \times 150 \mathrm{~km}$. No information on irregularity heights was available. Without knowing much about the thickness of the irregularity layer for the HF measurements (is it several kilometers or hundred kilometers?), the conclusions drawn from the ray tracing are not decisive. The effect of the irregularity filling the coherent radar beam has been studied by Walker et al. (1987).

For the event under consideration, we found that echo detection at the point of EISCAT observations (geomagnetic latitude of $\sim 66.5^{\circ}$ ) is strongly determined by the propagation conditions. The electron density distribution in the ionosphere must be appropriate to support radio wave propagation exactly to the expected area of joint observations, as in Fig. 7c.

Most of the echoes at the EISCAT observational area tended to occur during evening and midnight hours, the preferential period for Hankasalmi echoes at these latitudes (Milan et al., 1997). Echoes occurred for electron densities in between $1.0 \times 10^{11} \mathrm{~m}^{-3}$ and $4 \times 10^{11} \mathrm{~m}^{-3}$, which is exactly what is needed for radio wave focusing to the F-layer heights, according to the ray tracing analysis. The derived densities are consistent with the finding of Milan et al. (1997) that echoes typically occur for an F-layer critical frequency of $4 \mathrm{MHz}$.

One should say that during daytime/early evening hours in February 1999 stronger densities in the F-layer are usually achieved (according to the EISCAT measurements for 9, 10 and 11 February and according to the Sodankylä ionosonde statistics, see Milan et al. (1997), Fig. 7). Hence, the direct mode for F-region echoes should occur, if ever, at shorter distances. Hankasalmi echo occurrence rates published by Milan et al. (1997) do not have enough spatial resolution to see 


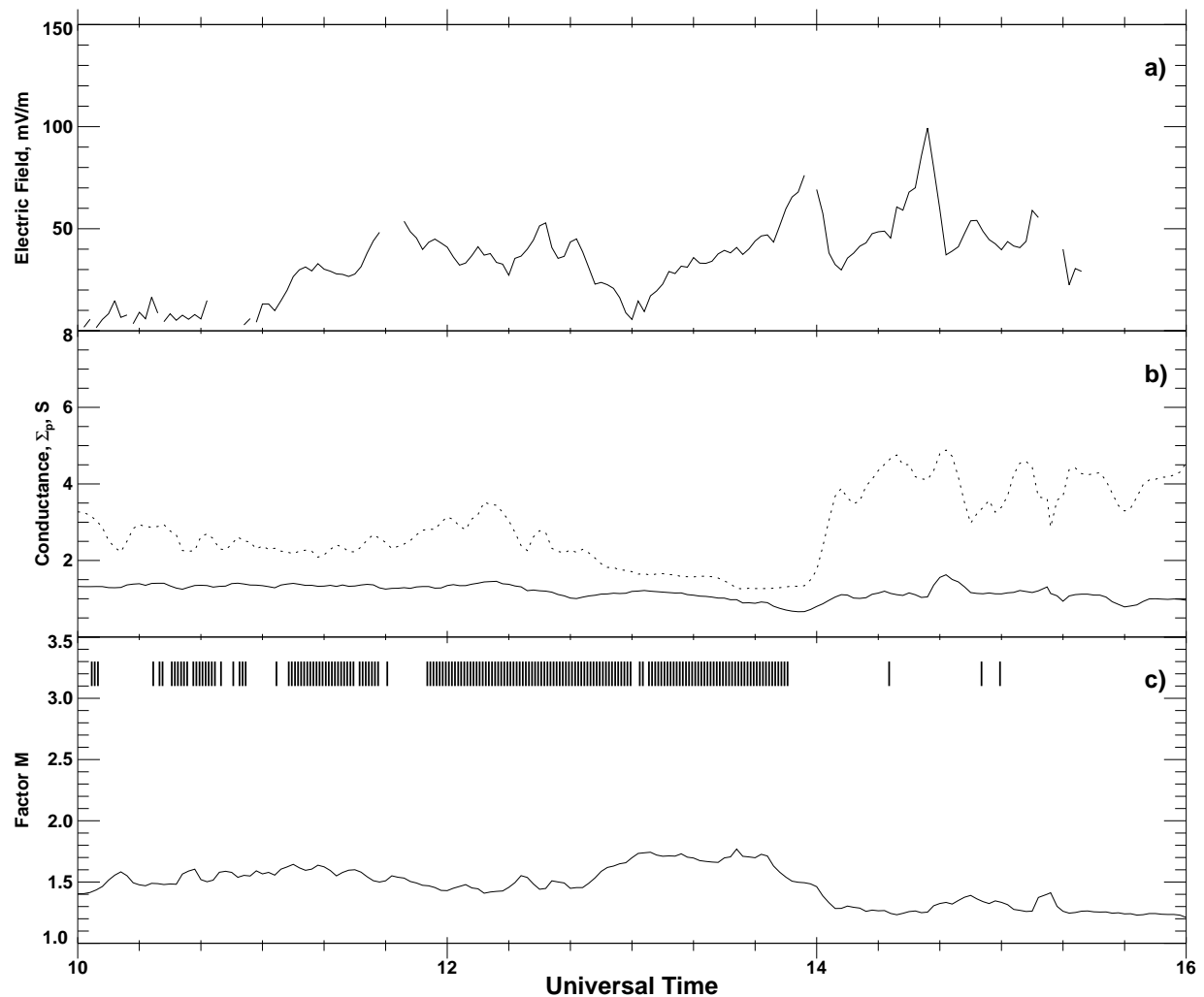

Fig. 10. The same as in Fig. 9, but for 12 February 1999 observations between 10:00 and 16:00 UT.

the effect, while Hosokawa et al. (2001) did not consider very low latitudes. Recent echo occurrence analysis performed by D. André (results are not published) confirms that maximum of echo occurrence for February 1999 is located at $2^{\circ}-$ $3^{\circ}$ lower than normal latitudes, in agreement with expectations. Our observations for 9, 10, and 11 February are also in agreement with this expectation. On 12 February, echoes were observed in the noon sector, but as we demonstrated, the densities were $\sim 2$ times smaller during this day.

One would expect another desirable effect with density increase, namely a better chance to obtain echo detection through the $1 \& 1 / 2$ propagation mode, since in this case, strong bending is more likely through refraction. Milan et al. (1997) clearly demonstrated that Hankasalmi daytime echoes are typically cusp/cleft echoes obtained through this mode, and other reports (e.g. Ruohoniemi and Greenwald, 1997; Hosokawa et al., 2001) support this conclusion.

One should mention that Hosokawa et al. (2001) found quite a few afternoon/evening echoes being produced at the poleward edge of the mid-latitude ionospheric trough. As we mentioned in Sect. 3, indeed echoes started to be observed more frequently right after the local sunset for the F-region, so the horizontal plasma gradient associated with the trough might have contributed well to the preferential irregularity formation during these hours. In addition, Hosokawa et al. (2001) did find a second morning peak in echo occurrence for the Canadian radars, but not for the Hankasalmi radar. In our event, quite a few echoes were observed during morn- ing hours on 10 and 11 February and perhaps on 9 February (EISCAT measurements are not available here, but Sodankylä ionosonde data support this conclusion) prior to local sunrise. One can conclude that F-region echoes at the EISCAT spot for February can be related to the trough. For certain, echoes are seen when the ionosphere experiences a transition from the daytime to the nighttime configuration in the evening sector and from the nighttime to the daytime in the morning sector.

Our conclusion of the primary role of refraction as a factor for the HF echo appearance refers to one specific point in the Hankasalmi radar field-of-view (FoV). It cannot be simply extrapolated to other areas within this radar FoV, not to say anything about other SuperDARN radars. Besides refraction, the issue here is whether strong F-region irregularities exist at all ionospheric heights accessible to radar waves. This is especially important for observations within the polar cap, where the background density is not strong enough to support refraction as it can in the auroral zone. Polar cap patches of F-region background ionization are important in two ways: they provide enhanced refraction and, on the other hand, the gradients at their edges are the primary areas for the excitation of the GD instability (Tsunoda, 1988). These clouds are certainly limited in their horizontal extent and height. So for the polar cap echoes the propagation conditions should be matched with the irregularity production conditions.

The prime importance of proper refraction conditions for echo appearance does not mean that other factors are not im- 
portant. First of all, with respect to the D-region absorption, we should mention that the events under consideration were, by chance, for quiet and moderately disturbed days. The absorption was very small at the range $(\sim 300 \mathrm{~km})$ where the rays that intersect the F-region at $\sim 900 \mathrm{~km}$ were passing through the D-region. Stronger absorption was detected at some larger ranges, which might affect scatter at ranges beyond $900 \mathrm{~km}$, although this assessment is complicated due to the presence of ground scatter at these ranges. We would expect more significant importance of D-region absorption during more disturbed days when the region of strong particle precipitation is shifted equatorward. It is well documented now that HF radar echoes quickly disappear at the expansive phase of a substorm developing in the local time sector of radar measurements (e.g. Voronkov et al., 1999).

The irregularity production factors are also important. For the considered events, the IMF $B_{z}$ component was mostly negative, so that one would expect mostly strong electric fields in the auroral zone, and the EISCAT measurements indeed show $E$ fields in excess of the $5-10 \mathrm{mV} / \mathrm{m}$ needed for the excitation of the GD instability. The daytime data presented in Fig. 8 indicate that echo power generally increases with electric field. This conclusion is consistent with the statistical analysis of the echo power-Doppler velocity relationship performed by Fukumoto et al. (1999, 2000). These authors found that the power of echoes increases with the 1-o-s velocity, clearly during daytime, and in more complicated fashion in the midnight sector. This is similar to our results, if one assumes that the 1-o-s velocity increases because of electric field enhancement (power variations with the flow angle are not expected for the F-region echoes, though analysis of this effect has not been done yet). One would expect the density fluctuation level increase with the electric field, since GD instability is strongly dependent on the electric field magnitude (Tsunoda, 1988).

Our analysis shows that besides a strong electric field, the conductance of the E-region must be taken into account when the irregularity production is considered; this conclusion is similar to one of Milan et al. (1999). For example, on 11 February, between 16:00 and 18:00 UT, the propagation conditions were satisfactory, $N_{e}=2 \times 10^{11} \mathrm{~m}^{-3}$, the electric field was of reasonable intensity, $20 \mathrm{mV} / \mathrm{m}$, and as a consequence of reasonably small $M$ values, echoes were not seen over the EISCAT spot. However, the situation was not always clear. Contrary to prediction, we showed that echoes were not always observed when $M$ factor values were large.

Several other effects can explain the echo absence over the EISCAT spot. One of these is that propagation conditions might have been such that one would need irregularities to be intense below $200 \mathrm{~km}$. It well might be that irregularities simply were not generated at these heights. It is expected that the GD instability is efficient at the edges of plasma clouds in the F-region, and it might be that ionospheric gradients were not strong enough to generate the irregularities, although with the current experiment, the horizontal gradient could not be measured. Further studies should be carried out to ascertain the effects of horizontal gradients on the produc- tion of F-region irregularities.

\section{Conclusions}

In this study, we attempted to evaluate the factors influencing the F-region echo appearance at a specific spot in the high latitude ionosphere. The monitored area was conveniently located for a direct HF propagation mode. A 4-day period was considered with 2 relatively quiet days and 2 moderately disturbed days. Overall, significant amounts of echoes were observed. We found that D-region absorption is a minor factor for the echo detection. Often absorption just decreased the power of the signals. We also demonstrated that echoes were more intense for a stronger electric field, though often, they occurred for a fairly low electric field of $\sim 10 \mathrm{mV} / \mathrm{m}$. The most significant factor that controls echo appearance was the electron density distribution in the ionosphere, both in the Eand F-regions. F-region density controls radio wave propagation/focusing to the test spot and the density needs to be in between $0.5 \times 10^{11} \mathrm{~m}^{-3}$ and $4 \times 10^{11} \mathrm{~m}^{-3}$. E-region density, besides supporting the propagation mode, may perhaps influence the wave electric field of F-region irregularities, so that in the case of a very dense E-region, the instability is slowed down or even prevented by the enhanced conductance.

Acknowledgements. CUTLASS Finland radar is supported by PPARC, the Swedish Institute for Space Physics, Uppsala, and the Finnish Meteorological Institute. EISCAT is an international facility supported by Finland, France, Germany, Japan, Norway, Sweden and the UK. Data of the Sodankylä ionosonde and Finnish riometers are from the Sodankylä Geophysical Observatory. Additional riometer data originated from the Imaging Riometer for Ionospheric Studies (IRIS), operated by the Department of Communications Systems at Lancaster University (UK), funded by the Particle Physics and Astronomy Research Council (PPARC) in collaboration with the Sodankylä Geophysical Observatory. The geomagnetic data are from the Troms $\varnothing$ Geophysical Observatory (Nordlysobservatoriet), University of Troms $\varnothing$, Norway. A.V.K. acknowledges the Solar-Terrestrial Environment Laboratory of the Nagoya University for funding during his stay in Japan. The work was also supported by an NSERC grant (Canada) to A.V.K. The authors are grateful to K. Schlegel and R. Woodman for helpful discussions.

The Editor in chief thanks two referees for their help in evaluating this paper.

\section{References}

Ballatore, P., Villain, J.-P., Vilmer, N., and Pick, M.: The influence of the interplanetary medium on SuperDARN radar scattering occurrence, Ann. Geophysicae, 18, 1576-1583, 2001.

Chaturvedi, P. K., Keskinen, M. J., Ossakow, S. L., and Fedder, J. A.: Effects of field line mapping on the gradient-drift instability in the coupled E- and F-region high-latitude ionosphere, Radio Sci., 29, 317-335, 1994.

Coffey, H.: Geomagnetic and solar data, J. Geophys. Res., 104, 22 819-22 820, 1999.

Fejer, B. G. and Kelley, M. C.: Ionospheric irregularities, Rev. Geophys., 18, 401-454, 1980. 
Fukumoto, M., Nishitani, N., Ogawa, T., Sato, N., Yamagishi, H., and Yukimatu, A. S.: Statistical analysis of echo power, Doppler velocity and spectral width obtained with the Syowa South HF radar, Adv. Polar Upper Atmos. Res., 13, 37-47, 1999.

Fukumoto, M., Nishitani, N., Ogawa, T., Sato, N., Yamagishi, H., and Yukimatu, A. S.: Statistical study of Doppler velocity and echo power around $75^{\circ}$ magnetic latitude with the Syowa East HF radar, Adv. Polar Upper Atmos. Res., 14, 93-102, 2000.

Greenwald, R. A., Baker, K. B., Dudeney, J. R., et al.: DARN/SuperDARN: A global view of the dynamics of highlatitude convection, Space Sci. Rev., 71, 761-796, 1995.

Hanuise, C.: High-latitude ionospheric irregularities: a review of recent results, Radio Sci., 18, 1093-1121, 1983.

Hosokawa, K., Iyemori, T., Yukimatu, A. S., and Sato, N.: Source of field aligned irregularities in the subauroral F-region as observed by the SuperDARN radars, J. Geophys. Res., 106, 24713 24731, 2001.

Hosokawa, K., Woodfield, E. E., Lester, M., Milan, S. E., Sato, N., Yukimatu, A. S., and Iyemori, T.: Statistical characteristics of spectral width as observed by the conjugate SuperDARN radars, Ann. Geophysicae, 20, 1213, 2002.

Huber, M.: HF radar echo statistics and spectral studies using SuperDARN, M.Sc. Thesis, University of Saskatchewan, Saskatoon, Canada, 1999.

Keskinen, M. J. and Ossakow, S. L.: Nonlinear evolution of plasma enhancements in the auroral ionosphere. 1. Long wavelength irregularities, J. Geophys. Res., 87, 144-150, 1982.

Milan, S. E., Yeoman, T. K., Lester, M., Thomas, E. C., and Jones, T. B.: Initial backscatter occurrence statistics from the CUTLASS HF radars, Ann. Geophysicae, 15, 703-718, 1997.

Milan, S. E. and Lester, M.: Simultaneous observations at differ- ent altitudes of ionospheric backscatter in the eastward electrojet, Ann. Geophysicae, 16, 55-68, 1998.

Milan, S. E., Davies, J. A., and Lester, M.: Coherent HF radar backscatter characteristics associated with auroral forms identified by incoherent radar techniques: A comparison of CUTLASS and EISCAT observations, J. Geophys. Res., 104, 22 591-22 604, 1999.

Ruohoniemi, J. M. and Baker, K. B. : Large-scale imaging of highlatitude convection with Super Dual Auroral Radar Network HF radar observations, J. Geophys. Res., 103, 20 797-20 811, 1998.

Ruohoniemi, J. M. and Greenwald, R. A.: Rates of scattering occurrence in routine HF radar observations during solar cycle maximum, Radio Sci., 32, N3, 1051-1070, 1997.

Tsunoda, R. T.: High latitude irregularities: A review and synthesis, Rev. Geophys., 26, 719-760, 1988.

Villain, J.-P., Greenwald, R. A., and Vickrey, J. F.: HF ray tracing at high latitudes using measured meridional electron density distribution, Radio Sci., 19, 359-374, 1984.

Villain, J.-P., Beghin, C., and Hanuise, C.: ARCAD3-SAFARI coordinated study of auroral and polar F-region ionospheric irregularities, Ann. Geophysicae, 4, 61-73, 1986.

Vickrey, J. F. and Kelley, J. D.: The effects of a conducting E-layer on classical F-region cross-field plasma diffusion, J. Geophys. Res., 87, 4461-4468, 1982.

Voronkov, I., Friedrich, E., and Samson, J. C.: Dynamics of the substorm growth phase as observed using CANOPUS and $\mathrm{Su}-$ perDARN instruments, J. Geophys. Res., 104, 28 491-28 505, 1999.

Walker, A. D. M., Greenwald, R. A., and Baker, K. B.: Determination of the fluctuation level of ionospheric irregularities from radar backscatter measurements, Radio Sci., 22, 689-705, 1987. 